\title{
Does Performance in Digital Reading Relate to Computer Game Playing? A Study of Factor Structure and Gender Patterns in 15-Year-Olds' Reading Literacy Performance
}

\section{Maria Rasmusson \& Lisbeth Åberg-Bengtsson}

To cite this article: Maria Rasmusson \& Lisbeth Åberg-Bengtsson (2015) Does Performance in Digital Reading Relate to Computer Game Playing? A Study of Factor Structure and Gender Patterns in 15-Year-Olds' Reading Literacy Performance, Scandinavian Journal of Educational Research, 59:6, 691-709, DOI: 10.1080/00313831.2014.965795

To link to this article: https://doi.org/10.1080/00313831.2014.965795

曲 Published online: 21 Oct 2014.

Submit your article to this journal $[\pi$

山 Article views: 466

Q View related articles $\longleftarrow$

View Crossmark data $\asymp$

Citing articles: 4 View citing articles $₫$ 


\title{
Does Performance in Digital Reading Relate to Computer Game Playing? A Study of Factor Structure and Gender Patterns in 15-Year-Olds' Reading Literacy Performance
}

\author{
Maria Rasmusson \\ Mid Sweden University \\ Lisbeth Åberg-Bengtsson \\ University of Borås
}

\begin{abstract}
Data from a Swedish PISA-sample were used (1) to identify a digital reading factor, (2) to investigate gender differences in this factor (if found), and (3) to explore how computer game playing might relate to digital reading performance and gender. The analyses were conducted with structural equation modeling techniques. In addition to an overall reading factor, the hypothesized digital reading factor was identified. When the overall reading performance was taken into account, a relative difference in favor of the boys for digital reading was indicated. This effect was mediated by a game-playing factor comprising the amount of time spent on playing computer games. Thus, the boys' better performance in digital reading was explained by the computer game-playing factor.
\end{abstract}

Keywords: digital reading literacy, gender differences, computer game playing, the PISA literacy assessment

In contemporary society, modern communication and information technology is used by a constantly growing number of people in most countries. Computer and video games, as well as games on hand-held devices, are widespread and occupy a large part of people's leisure time. Students' use of the new technologies has increased both during school hours and outside school. For example, on average in 2009, 93\% of 15-year-olds in Organisation for Economic Cooperation and Development (OECD) countries used computers at home, whereas $71 \%$ used them at school. In Sweden, these figures amounted to $98 \%$ and $89 \%$, respectively (Swedish National Agency for Education, 2011). Thus, in addition to traditional literacy, both the mastery of this new medium and good digital reading skills are becoming not only of increasing importance, but also a necessity for people worldwide.

In line with this trend, the well-established OECD Programme for International Student Assessment (PISA) expanded its reading framework to include digital reading, arguing that the definition of reading literacy in the 21 st century needs to encompass both printed and digital texts (OECD, 2009a). Thus, a digital reading literacy section was offered as an

Maria Rasmusson, Department of Education, Mid Sweden University; Lisbeth Åberg-Bengtsson, School of Education and Behavioural Sciences, University of Borås.

Correspondence concerning this article should be addressed to Maria Rasmusson, Mid Sweden University, Department of Education, Universitetsgatan 1, Härnösand 871 88, Sweden. E-mail: maria.rasmusson@miun.se 
option in the international assessment administered in 2009 (henceforth referred to as "PISA 2009"). Digital reading refers to reading that implies navigation and information search in hypertext; in other words, reading on the Internet. Thus, the reader must be familiar with explicit and embedded hyperlinks, non-sequential page structures, as well as with global content representation devices (OECD, 2009a). In the present article, digital reading is used in this way.

Sweden was one of the countries to include the digital reading section in the assessment to a subsample of the test takers. The reported general results, as such, as well as the results for the Swedish sample, follow the oft-found pattern of girls outperforming boys in reading literacy ability (OECD, 2011). This was the case for both traditional and digital reading. Controlling for traditional reading, though, rendered a relative advantage for boys with respect to digital reading. However, the rich body of data offered in the OECD survey enables in-depth studies and more far-reaching analyses. The present article focuses on gender differences in digital reading performance for the Swedish sample and is conducted with confirmatory factor analyses and structural equation modeling techniques.

\section{Background}

A number of aspects may be relevant to consider when investigating and discussing digital reading performance and gender issues. Below, research and theories focusing on demands of particular skills on digital reading (if any) and gender differences in reading performance are brought to the fore, along with the issue of computer habits and digital performance.

\section{Digital Reading May Demand Particular Skills}

A number of studies of digital reading argue that skills and abilities needed for digital reading are, to some extent, different from those required for traditional reading of printed text. Leu et al. (2007) compared online and offline reading skills among seventh-grade students. From their results, they claim that online and offline reading comprehension does not seem to be fully isomorphic. This is in line with Coiro's (2003) arguments that we need to find new constructs of reading comprehension and that students need to be introduced to strategies to master these new literacies. According to Coiro (2011):

Skilled online readers move through a complicated process of navigating search engines and disparate Web site structures and negotiating multiple modes of information and a diverse range of perspectives. This process involves strategies for determining important ideas, judging the relevance of those ideas in relation to their purpose, investigating author credentials, detecting author agendas, and corroborating questionable claims. (p. 109)

A body of research in the area of digital reading indicates that abilities such as multimodal literacy, path-finding, IT abilities, inferential reasoning strategies, and self-regulated reading processes as well as being able to evaluate sources and construct coherent representations of the content are important to reading performance on the Internet (Coiro, 2011; Coiro \& Dobler, 2007; Rasmusson \& Eklund, 2013; Strømsø, Bråten, \& Samuelstuen, 2008). 
The examples above relate to differences between traditional and digital reading. Other scholars have attended to digital media per se. Already some two decades ago, Kress and van Leeuwen (1996) stated that the semiotic landscape was changing and that new technologies give us a visual representation of the world that differs from that in printed pages. They argued that schools should involve new technologies and a "new literacy" in their curricula in order to adapt to this new semiotic landscape. In line with this, Gee (2003) raises the issue that digital texts often are multimodal and include, for instance, pictures, sounds, and videos, as well as words, and thus demand multiple skills. Consequently, it is important to recognize the presence of multiple literacies.

\section{Gender Aspects on Reading in Different Semiotic Modes}

In the large corpus of research on traditional reading literacy, a reoccurring pattern is that boys underperform girls in compulsory school (e.g., Asher \& Gottman, 1973; Donahue, Finnegan, Lutkus, Allen, \& Campbell, 2001; Elley, 1994; Gates, 1961; Newkirk, 2000; OECD, 2010; Smith \& Wilhelm, 2002; Taube \& Munck, 1996; Wagemaker, 1996). This seems to be the case also for digital reading. For example, some recent studies of PISA data point into this direction (OECD, 2011; Thomson \& De Bortoli, 2012).

However, previous research, some of which will be referred to below, gives us reason to believe that the gender patterns in reading performance may be more complex and multifaceted than an initial analysis of a survey may suggest. A number of research projects provide a more detailed picture of gender differences in both traditional and digital reading. For example, it is well known that reading performance is related to motivation, interest, and attitudes towards reading in general as well as towards particular types of texts (e.g., Anmarkrud \& Bråten, 2009; McKenna, Conradi, Lawrence, Jang, \& Meyer, 2012; Retelsdorf, Köller, \& Möller, 2011). Rosén (2001) analyzing data from the International Association for the Evaluation of Educational Achievement Reading Literacy study for 9- and 14-year-olds, found an expected gender difference in favor of girls in overall, traditional reading performance but no consistent gender difference in "document reading" (i.e., the reading of Tables, diagrams etc.).

With respect to digital reading, McKenna et al. (2012) found that middle-school female students in the USA had more positive attitudes than males toward academic reading in both digital and print settings. However, concerning recreational reading in a digital setting, the males were more positive than the females. Furthermore, detailed analyses of the results from the PISA assessment in 2009 suggest that boys have better digital navigation skills than girls. Boys also seemed to be more engaged with digital texts than traditional printed texts (OECD, 2011; Thomson \& De Bortoli, 2012). As already touched upon, PISA's digital reading assessment also showed that boys had an advantage over girls when print reading performance was controlled for (OECD, 2011).

\section{Reading Performance and Cognitive Abilities}

Both cognitive ability factors in general and gender differences in such factors are frequently researched areas. For instance, it has long since been a well-established outcome of this research that males tend to perform better than females on tests of visual-spatial ability (e.g., Bennett, Seashore, \& Wesman, 1974; Maccoby \& Jacklin, 1974; McGee, 1979). 
Below, pieces of research relating to cognitive abilities, computer games, and reading performance will be reviewed.

\section{Computer game playing related to cognitive abilities.}

Three similar research projects from the 1980s and 1990s (McClurg \& Chaillé, 1987; Okagaki \& Frensch, 1994; Subrahmanyam \& Greenfield, 1994) investigated American students' spatial performance before and after periods of playing computer games. All three studies rendered similar results - computer games were argued to enhance spatial ability for both the girls and the boys. Subrahmanyam and Greenfield's (1994) study also showed that the gender gap in favor of boys was narrowed.

More recently, Feng, Spence, and Pratt (2007) showed that a group of experienced actiongame players were superior to a group of non-players in spatial selective attention. They found no gender difference in the players' group, while there was a statistically significant difference in favor of the males in the non-players' group. A follow-up experiment showed that undergraduates who got practice with a first-person shooter game increased their performance in a spatial attention test and that females benefited more than males from the video game practice.

An investigation by Greenfield et al. (1996) indicated that the ability to read images, such as pictures and diagrams, was enhanced by playing a non-violent computer game. In another study with a visual focus Greenfield, deWinstanley, Kilpatrick, and Kaye (1994) concluded that playing computer games may enhance visual attention, that is to say, the ability to keep track of a lot of different processes at the same time.

The research referred to above makes it reasonable to assume that frequently playing computer and video games may improve visual-spatial ability as well as visual attention and the reading of images.

\section{Visual-spatial ability related to digital reading.}

Linking visual-spatial ability to web activities in general is common when discussing digital literacy of different kinds (e.g., Castelli, Colazzo, \& Molinari, 1998; Lee, 2007; Pan et al., 2004; Protopsaltis \& Bouki, 2009; Zhang \& Salvendy, 2001). Some of these scholars have investigated, in empirical studies, the effect of this ability on literacy in the digital environment. Lee (2007), testing students, who had used a web-based learning material, found that students with high spatial ability outperformed students with low spatial ability.

Castelli, Colazzo, and Molinari (1998) studied the phenomenon of disorientation in hypertext in relation to cognitive abilities among middle-school students. Males who had higher spatial abilities than females performed better than these females in navigation, whereas females who achieved better in logical efficiency performed better than the males on the hypertext tasks. Zhang and Salvendy (2001) investigated the effect of visual-spatial ability in web information search tasks in two different types of websites. Students with high visual-spatial ability performed better on the tasks in a conventionally structured website than the low spatial-ability group. Zhang and Salvendy concluded that spatial ability plays a role in information search, and that users with low visual-spatial ability may benefit from visual mediators in a human-centered web structure. 
The studies in the present section indicate that learning from and navigating in digital environments, such as web pages and hypertext, might benefit from good spatial abilities, even though other cognitive abilities may compensate for this in particular contexts.

\title{
In sum.
}

Even though there is still a rather modest body of research on digital reading, previous studies indicate that digital reading partly differs from traditional reading and thus partly requires different skills. For example, digital reading certainly demands the ability to navigate through different web pages and the ability to use hyperlinks and navigation tools. It has been suggested that computer and video game playing might enhance particular cognitive skills such as visual-spatial ability, which in turn, according to some researchers, might improve certain aspects of reading and learning from web-based environments.

A number of studies indicate that the picture of gender differences in reading literacy performance is more complex than what is shown by the reoccurring pattern that girls on average perform better than boys in reading assessments.

\begin{abstract}
Aim
Considering the presentation above, a number of issues assumed to be related to digital reading can be brought to the fore. First, it has been argued that the abilities required for digital reading might be somewhat different from those involved in traditional reading. Following up this issue, the present study deals with how performance in digital reading is related to performance in traditional reading. Second, in PISA 2009, a smaller gender difference in favor of girls was noticed for digital reading than for traditional reading. The question that arose was whether this deviation would be possible to validate with a more advanced methodological approach. Third, in previous research, computer game playing has been argued to influence visual-spatial ability, on the one hand, and, on the other hand, visualspatial ability has been found to affect aspects of web-based activities that are certainly involved in digital reading. Thus, an interesting thread to be followed is whether the influence of computer game playing can be related to digital reading performance.

Using data from the PISA 2009 survey, the aim is to investigate the factor structure and gender patterns in Swedish 15-year-olds' reading literacy performance and to investigate computer game playing in relation to digital reading. Three research questions were posed:

- Is it possible to identify a digital reading factor in addition to an overall reading factor?

- How does this factor (if identified) relate to gender?

- Can time spent on computer game playing explain gender differences (if any) in digital reading performance?
\end{abstract}

The results will be discussed in the light of previous research and educational implications.

\section{Methods}

In this section, a description of the PISA data used in the study will be provided, followed by a presentation of methodological issues and considerations. 


\section{Reading Literacy Assessment in PISA}

On each occasion of a PISA administration, one of the three subjects reading literacy, mathematics, or science appears as the main theme. In 2009, the focus was on reading literacy and for the first time, a digital reading test was administered as an option in addition to traditional reading (OECD, 2010). The framework, which applies to both traditional and digital reading, defines reading literacy as "understanding, using, reflecting on and engaging with written texts, in order to achieve one's goals, to develop one's knowledge and potential, and to participate in society" (OECD, 2010, p. 37). Thus, PISA has adopted an expanded concept of text when relating this definition also to digital reading. However, written text in the digital test differs from traditional print text regarding "physical readability; the amount of text visible to the reader at any one time; the way different parts of a text and different texts are connected with one another through hypertext links" (OECD, 2009a, p. 24). Considering the design of the tasks in the traditional and the digital sections, the definition includes written texts and information presented in different kinds of graphic representations. In PISA 2009, "Traditional reading literacy" and "Digital reading literacy" were tested with two separate measures.

The traditional literacy assessment part is organized into three broad aspects of reading that may be regarded as mental strategies. The aspects imply that the students should: (1) Access and retrieve information in the text, (2) Integrate and interpret what they read, and (3) Reflect and evaluate, that is to say, stand back from the text and relate it to their own experience (OECD, 2010, p. 38). Each reading task is designed primarily to assess one of these three aspects. An Access and retrieve task "can range from locating the details required by an employer from a job advertisement, to finding a telephone number with several prefix codes, to finding a particular fact to support or disprove a claim someone has made" (OECD, 2009a, p. 35). Integrate and interpret tasks can imply comparing and contrasting information, explaining the order of simple instructions or identifying the main dimensions of a graph or a table. Other tasks in this category can ask for descriptions of the main character or setting of a story, identifications of the theme of a literary text, and explanations of purposes or the reading of maps or figures. There are two sub-aspects pointed out within the Reflect and evaluate category. One concerns the content of texts and the other the form of texts (OECD, 2009a).

The traditional reading literacy test was part of the two-hour, main-body, paper-based assessment, which included mathematics and science as well. The reading test consisted of units with "stimuli," that is to say, texts to be read, in some cases along with tables, charts, illustrations, and so on. Each stimulus covered one, two, or three pages and had two to five related questions. These questions had different formats. The students were either asked to answer open-ended or multiple-choice questions, or sometimes to draw the answer in a map or a picture. Depending on type of task, they had to retrieve, integrate, reflect, or evaluate the information. A stimulus together with its tasks formed a unit. A total of 28 units were grouped into seven clusters. Between one and four reading clusters were placed in one of 13 booklets, along with science and mathematics clusters in different combinations. Each student was presented one of these booklets containing a total of four clusters. Thus, due to this rotated design of the data collection, no student had to solve all tasks and not even the same number of tasks.

The digital reading literacy was assessed in a separate 40-minute, computer-based test. There were a total of nine units, and each student was assigned six of these in a rotated design. As in the traditional reading assessment, a unit contained a stimulus (e.g., texts, 
Tables, charts, figures, etc.) but in this case with two to four associated tasks. However, in the digital reading assessment, the stimulus contained web pages with links. Thus, the student had to navigate through different hypertext pages to access the information, whereas in the traditional reading assessment, all stimuli were presented in close connection with the tasks. ${ }^{1}$

\section{Conducting the Present Study}

It is frequently claimed that individuals' results on cognitive tests are not related to only one ability. Instead, a number of factors or dimensions at different levels of generality are proposed. Such hierarchical structures, which may be formulated and set up in different ways, have for a long time been convincingly argued for by, for example, Carroll (1993) and Gustafsson (1994). In the present study, nested factor modeling is used. In this alternative, suggested by Gustafsson and Balke (1993), an overall factor influencing all performance is related to all observed variables and less general factors are nested within it.

Below, a presentation of the methodological aspects related to factor analyses will be given before dealing with sample, data, and the preparation of data.

\section{Structural equation modeling and confirmatory factor analysis.}

In order to reach the objectives of this study, a confirmatory factor analytic approach using structural equation modeling techniques was adopted.

When data are clustered, as is the case within the PISA program where students are sampled by schools, particular caution is needed when conducting the analyses. Students attending the same school may be affected by, for example, the same environmental factors and school climate, and they may thus be suspected to be more similar to each other than students from an entirely independent sample would have been (e.g., Coleman, 1988).

In the present study, a disaggregated modeling approach, a two-level analysis, is applied in order to take the sampling design into account, which makes it possible to estimate and compare the components of variation at the two levels of the data hierarchy (Muthén \& Satorra, 1995).

\section{The present sample.}

In a PISA study, a complex two-stage sampling process is used to guarantee that the samples are representative of the national populations of 15-year-old students (for details, see OECD, 2010). Prior to sampling, the schools with 15-year-olds in a country are stratified into a sampling frame with respect to type of school, size, and other characteristics of their municipalities. Then, in the first stage, the schools are sampled and thereafter, in the second stage, students within these schools are chosen. Sweden uses 12 stratification variables building upon the type of school (independent or public) and type of municipality. Following this procedure 4,567 students were selected for the Swedish national sample. All these students completed the paper and pencil test.

\footnotetext{
${ }^{1}$ For further information and released tasks in the two environments, see http://www.oecd.org/pisa/ pisaproducts/pisa-test-questions.htm
} 
Table 1

Observed Variables Used in the Analysis

\begin{tabular}{|c|c|c|c|c|c|}
\hline Variable label & PISA section & Description & $M$ & $S E$ & $S D$ \\
\hline T_ACCESS & $\begin{array}{l}\text { Traditional } \\
\text { reading }\end{array}$ & Access and retrieve, plausible value & 511.4 & 3.4 & 101.4 \\
\hline T_INTEGRATE & $\begin{array}{l}\text { Traditional } \\
\text { reading }\end{array}$ & Integrate and interpret, plausible value & 501.0 & 3.3 & 100.7 \\
\hline T_REFLECT & $\begin{array}{l}\text { Traditional } \\
\text { reading }\end{array}$ & Reflect and evaluate, plausible value & 509.3 & 3.5 & 98.3 \\
\hline DIG_READ & Digital reading & Composite measure, plausible value & 515.9 & 3.5 & 87.0 \\
\hline ONE_GAME & Questionnaire & $\begin{array}{l}\text { Time spent on playing one-player games on } \\
\text { computer at home }\end{array}$ & 2.3 & 0.03 & 1.2 \\
\hline COLL_GAME & Questionnaire & $\begin{array}{l}\text { Time spent on playing collaborative online games } \\
\text { on computer at home. }\end{array}$ & 2.4 & 0.03 & 1.2 \\
\hline
\end{tabular}

From this larger sample and subsample of approximately $42 \%$ of the students ( 943 boys and 978 girls from 179 schools) were selected for the computer-based digital reading test. The Swedish PISA national center that performed the selections used the KeyQuest sampling software provided by the Australian Council for Educational Research for the procedure (OECD, 2012). As these 1,921 students constitute the group that took both the traditional print test and the digital reading test, they were used as subjects in the present study.

\section{Data.}

Plausible values ${ }^{2}$ from PISA 2009 for students' performance on the three aspects of traditional reading plus the one on the digital reading are used as observed variables in the present study in addition to two questions from the questionnaire (Table 1 gives an overview of these variables as well as an account of descriptive statistics). The reliability estimates for the reading measures in the Swedish sample were 0.91 for T_ACCESS, 0.91 for T_INTEGRATE, 0.92 for T_REFLECT, and 0.90 for DIG_READ (OECD, 2012).

The questions from the questionnaire provide information about time spent at the computer, playing one-player games, and collaborative online games. The students were asked, "How often do you use a computer for following activities at home? (a) Play one-player games (b) Play collaborative online games." For each question, one of the following four alternatives was to be chosen: "Never or hardly ever; Once or twice a month; Once or twice a week; Every day or almost every day."

As these measures build upon the students' own reports, it can, on the one hand, be argued that they may be rather imprecise. On the other hand, playing games on the computer is something that engages many students, and they do probably have a rather good idea of how much time they spend on such activities.

\footnotetext{
${ }^{2}$ When computing a plausible value, a mathematical distribution around a reported value is first calculated and then each observation is assigned a set of random values drawn from this distribution (OECD, 2009b). Such a procedure reduces errors in the analysis on the population level, which, in accordance with the aim of such surveys, is valued higher than reducing errors on the individual level.
} 


\section{Preparing data for analysis.}

In addition to the Mplus 7 estimation program (Muthén \& Muthén, 2012), the STREAMS 3.0.5 modeling environment (Gustafsson \& Stahle, 2005) was used. The data imputation command in Mplus can handle more than one plausible value at a time in a correct way. Thus, in order to obtain accurate standard errors, this option was used to create five data sets with plausible values for the analysis. Weights are used according to common practice in analysis of PISA data (Asparouhov, 2009).

Because all students receive plausible values for the three traditional reading aspects and for their digital reading performance, the reading variables are not missing any data. With regard to the two questions about computer habits from the questionnaire used in analysis, a small number of students left out one or both of them. For the ONE_GAME variable, the attrition was 57 answers, and for the COLL_GAME variable, it was 47 (i.e., 3\% and $2 \%$, respectively). Because the option in Mplus (Muthén \& Muthén, 2012) to impute missing values in accordance with missing data theory was used, all 1,921 subjects were included in the analysis.

\section{Analysis and Results}

In the presentation below, latent variables or factors (i.e., unobservable constructs) are denoted by letters in italics and the manifest (i.e., the observed) variables by upper-case letters. In the figures, the manifest variables are illustrated by rectangles and latent variables by ovals. One-way arrows point out one-way relationships starting at the independent variable, whereas two-way bent arrows indicate covariance. Residuals are denoted by ampersands in the hypothesized model.

The testing of models was accomplished with the Mplus 7 program (Muthén \& Muthén, 2012) using the maximum likelihood parameter estimator with the options "two-level complex analysis" and "data imputation." The presentation below follows the stepwise process in which the analysis was conducted. This is, on the whole, in line with the three research questions. However, we will begin by introducing the hypothesized model.

\section{The Hypothesized Model}

In accordance with the conventions of confirmatory factor analysis, a model was hypothesized from previous knowledge and theoretically well-grounded assumptions. This model (presented in Figure 1) includes two latent ability factors. An overall reading-ability factor, Overall reading, was assumed to influence all reading performances and was related to the three manifest variables corresponding to the three aspects of traditional reading (T_ACCESS, T_INTEGRATE and T_REFLECT) and to the manifest variable for digital reading (DIG_READ).

A second latent variable Digital reading nested within Overall reading was assumed to underlie digital reading performance and was only related to the digital reading variable. In addition to the four observed variables from the literacy tests, the two questions from the students' questionnaire ONE_GAME and COLL_GAME (with information about how much time the students spent on playing computer games at home) were included in the hypothesized model as manifest variables. 


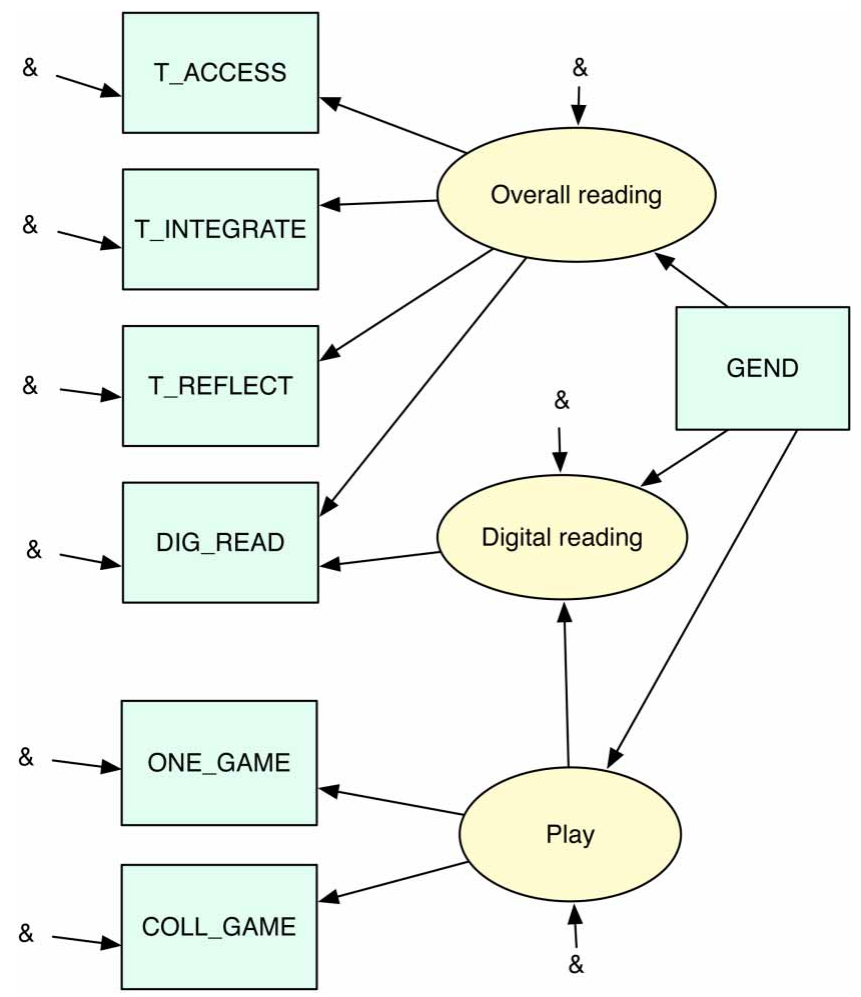

Figure 1. The hypothesized model on student-level. Standardized values.

The third latent variable Play was related to these two variables. In addition, this latter factor Play was assumed to influence the digital reading ability factor Digital reading. As gender differences were in focus in the analysis, a manifest gender variable (GEND) was related to these three factors.

\section{The Measurement Model}

A measurement model where the four manifest variables T_ACCESS, T_INTEGRATE, T_REFLECT and DIG_READ were assumed to load on the latent overall reading literacy factor Overall reading was set up and computed in the first step. At this stage of the analysis, no decomposition of variance between group and individual levels was yet conducted. The factor loadings, which are the relationships between the manifest variables and the factor, were substantial and the model fit was good: $\chi^{2}(2)=1.34, \mathrm{RMSEA}=.00, \mathrm{CFI}=1.00$, and $\mathrm{TLI}=1.00$. See Figure 2 for factor loadings and residuals.

\section{Identifying a Nested Digital Reading Factor}

Next, the measurement model was expanded by including the digital reading literacy factor Digital reading nested within the overall reading literacy factor Overall reading. This model uses the residual in the manifest digital reading variable (DIG_READ) to 


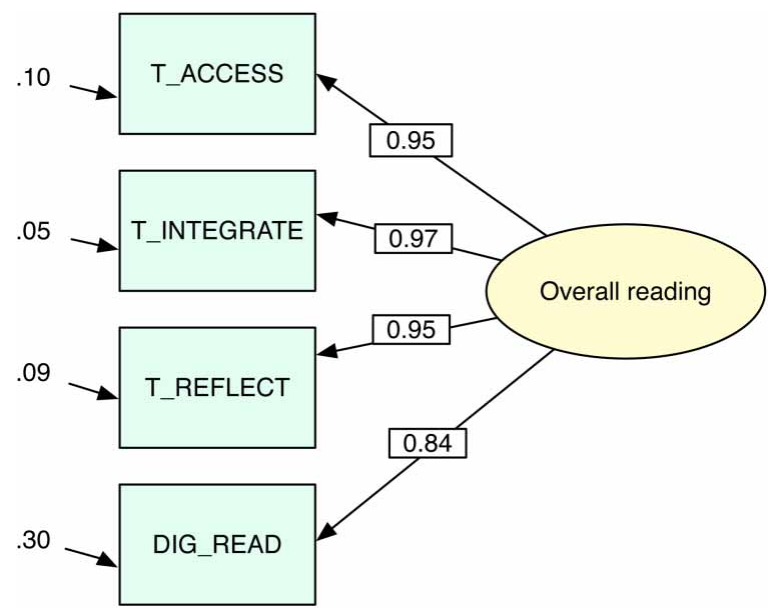

Figure 2. The measurement model. All relationships are statistically significant. Standardized values.

establish a latent digital-reading factor Digital reading related to one manifest variable only. For the observed variable DIG_READ, the reliability measure obtained from the OECD (2012) report was used, in addition to the variance from the STREAMS estimation, to separate the residual variance from the systematic variance. The calculations were conducted from the total variance for the present one-level model, and from the student-level part of the decomposed variance for the two-level models below. As the residual for DIG_READ was thus specified in the models, a relatively unbiased estimate was obtained for the latent Digital reading variable.

The model estimation shows a substantial standardized factor loading (0.47) for DIG_READ on Digital reading and a good fit: $\chi^{2}(2)=1.34$, RMSEA $=.00$, CFI $=1.00$, and TLI $=1.00$. The standardized factor loadings achieved for the other relationships of this model were the same as those in the measurement model and statistically significant. This indicates that the model works well.

\section{Decomposing Within- and Between-Group Variances}

Intraclass correlations were computed and found to be substantial, ranging between .17 and .20 for the three aspects related to traditional reading, and amounting to .24 for the digital reading measurement. Consequently, the amount of variance related to the school level was impossible to ignore. However, as only the individual level was of interest in our study, the school-level variance was separated out by simply allowing the manifest variables on the second level to co-vary, when, henceforth in the analysis, computing two-level models. The two-factor model above rendered a decent fit $\left(\chi^{2}[2]=5.27, \mathrm{RMSEA}=.03, \mathrm{CFI}=\right.$ 0.99 , TLI $=0.99)$ when converted into a two-level model in this vein. The factor loadings differed only marginally from those in the previous models.

\section{Relating Gender to the Reading Factors}

At this stage of the analysis, the gender variable GEND was introduced. This variable was dichotomously coded, with the girls given the value one and the boys set to zero. Initially, in 


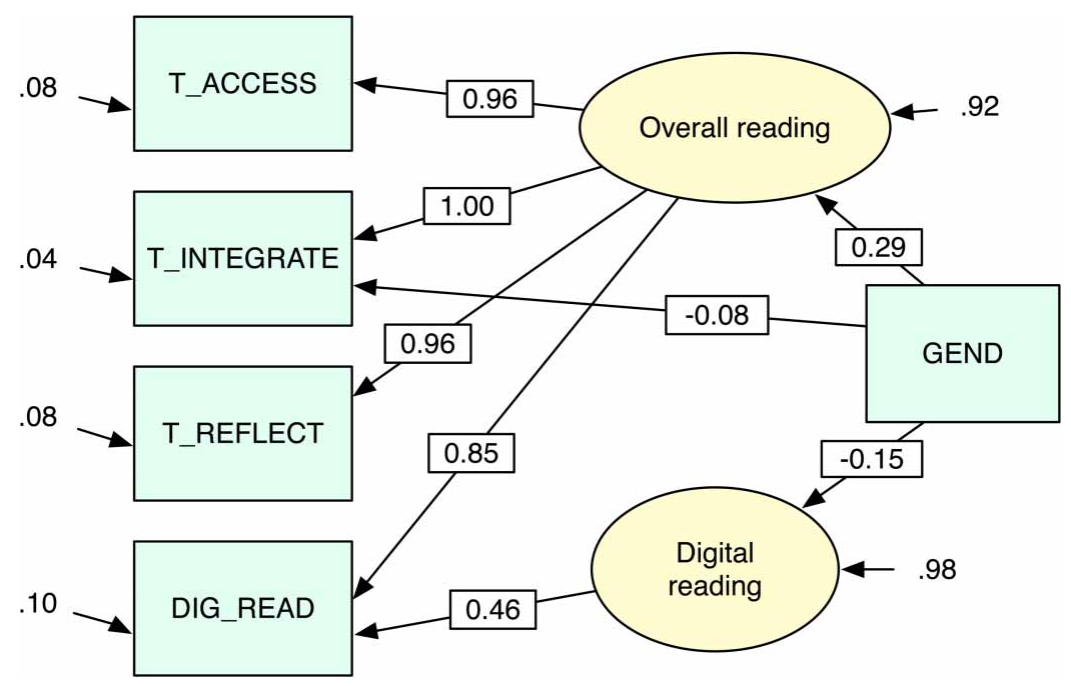

Figure 3. The student-level part of the two-level model. All relationships are statistically significant. Standardized values.

accordance with our hypothesized model, GEND was related to the Overall reading and Digital reading factors. However, even though the relationships between GEND and the factors were statistically significant with values, standardized on $\mathrm{Y}$, of 0.26 and -0.09 , respectively, the model fit was poor $\left(\chi^{2}[4]=92.20\right.$, $\mathrm{RMSEA}=.11, \mathrm{CFI}=0.99$, and $\mathrm{TLI}=$ 0.95), which indicated that there were gender differences still not accounted for. As a consequence, a modification of the model was necessary.

It was found that the model fit was improved by relating gender to the manifest variable T_INTEGRATE. Thus, in this phase, the analysis was not genuinely confirmatory but, rather, what Jöreskog and Sörbom (1993) label "model generating." This modified model showed a satisfying fit $\left(\chi^{2}[3]=11.93\right.$, RMSEA $=.04$, CFI $=1.00$, and TLI $\left.=0.99\right)$.

As can be seen in Figure 3, a substantial gender difference in favor of girls was found in the overall reading literacy performance Overall reading. However, with this taken into account, the boys performed better in digital reading and with regard to the "integrate and interpret" aspect in traditional reading (T_INTEGRATE). The correlations were $0.29(t=$ $25.1)$ between GEND and Overall reading, and $-0.15(t=3.2)$ between GEND and Digital reading. The correlation between GEND and T_INTEGRATE was $0.08(t=-7.2)$. The values in Figure 3 and 4 are standardized on both $\mathrm{X}$ and $\mathrm{Y}$ but they were the same when standardizing on $\mathrm{Y}$ only.

\section{Mediating the Gender Effect in Digital Reading Performance With a Playing Factor}

In line with the hypothesis, the two questions, ONE_GAME and COLL_GAME, from the students' questionnaire were added to the model and set to load on the factor Play. This factor was, in turn, set to influence the digital reading factor Digital reading. The gender variable was related to the three factors. This model rendered good fit indices: $\chi^{2}(11)=33.01$, RMSEA $=.03$, CFI $=0.99$, and TLI $=0.99$. As can be gathered from Figure 4, there was an indirect effect by gender on Digital reading via the Play factor 


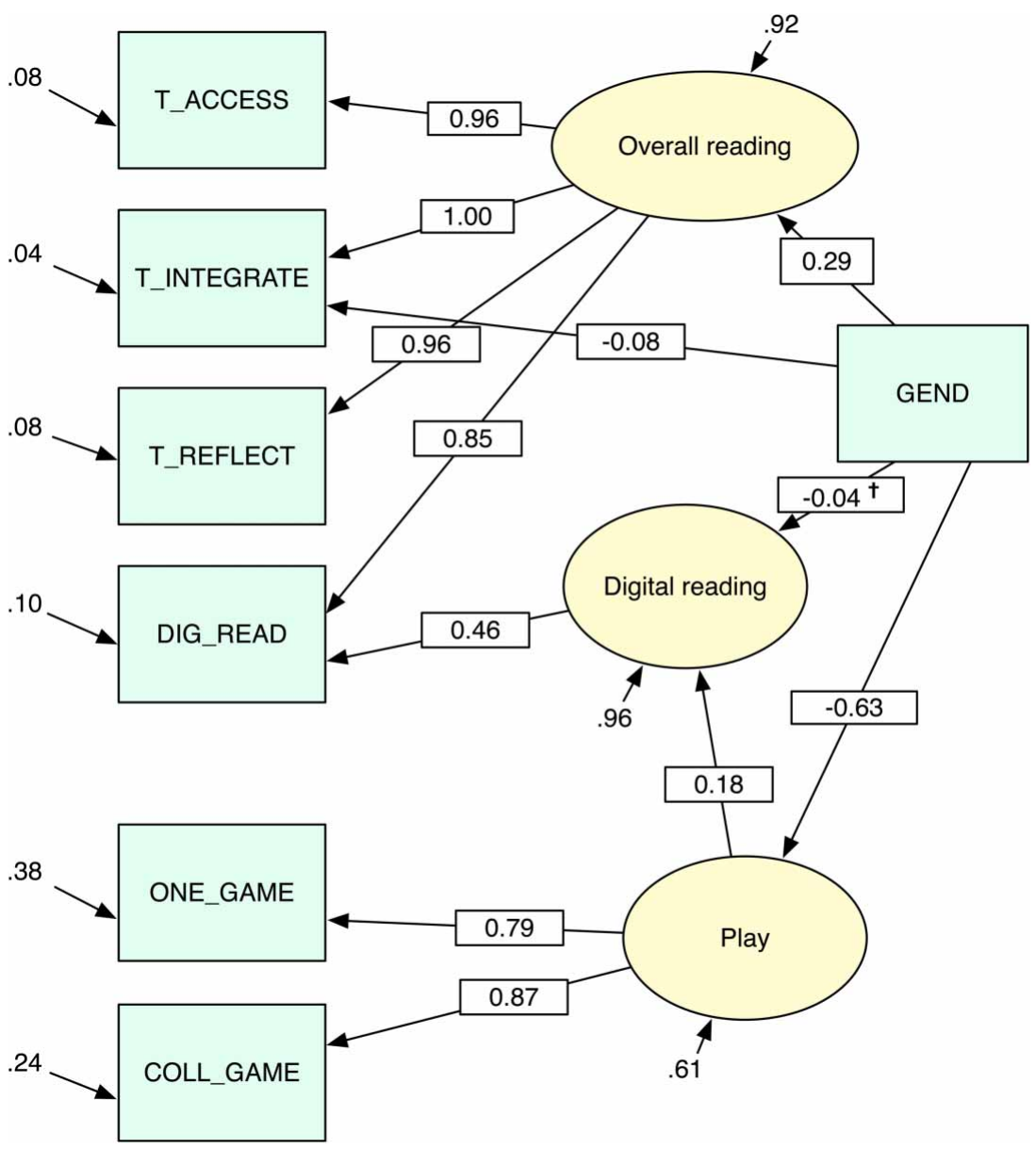

Figure 4. The student-level in the three-factor model. The dagger indicates a non-significant value. Standardized values.

replacing the previously obtained relationship between gender and Digital reading. Stated differently, the gender difference in favor of boys with respect to digital reading literacy in the previous model was perfectly mediated by time spent on playing computer games in this final model, even though, the direct effect size for this path was relatively small. The correlation between GEND and Play amounted to $-0.63(t=-23.8)$, and between Play and Digital reading it was $0.18(t=2.43)$. The standardized indirect effect size for the path GEND-Play-Digital reading was $-0.09(t=-3.29)$, when estimated using bootstrapping as suggested by Preacher and Hayes (2008). When the mediating factor was added, the path from GEND to Digital reading became insignificant and rendered the value $-0.04(t=-0.78)$.

\section{In Sum}

We investigated the gender differences in reading literacy performance with a focus on digital reading for the Swedish sample of PISA 2009 by using the structural equation 
modeling technique. In addition to an overall reading factor, a digital reading factor was identified to explain a minor part of the variance.

In our initial computations, the expected and frequently reported difference in favor of girls in overall reading performance was verified. However, when this overall performance was taken into account, there was a significant, relative difference in favor of boys for digital reading, which is in line with earlier studies on this data conducted with less elaborated techniques (OECD, 2011). When further investigating this latter effect, we found that it was perfectly mediated by the game-playing factor. This means that the boys' (relatively seen) better performance in digital reading was explained by the playing factor related to the amount of time spent on one-player games and collaborative games.

\section{Concluding Discussion}

The aim of the present study was to investigate the factor structure and gender patterns in Swedish 15-year-olds' reading literacy performance using data from the PISA 2009 survey. In this section, the results are first interpreted in the light of previous research. Then some possible implications for education are pointed out before final remarks are made.

The set-up and testing of a particular digital reading factor nested within an overall reading dimension stemmed from an assumption that more complicated processes of navigation might be involved in the digital reading assessment of the PISA 2009 survey compared to those involved in the traditional reading test. This hypothesis of ours was partly based on suggestions proposed in reports of previous research (e.g., Coiro, 2003; Leu et al., 2007) that demands on digital reading ability might not be fully isomorphic with those on traditional reading. In addition, we observed that the digital reading assessment of the PISA 2009 survey included elements unique for the particular digital environment constructed for this part of the test, elements that had no correspondence in the traditional printed test. This raised questions about if these unique elements and the digital environment require particular skills additional to those needed in traditional print reading. The identification of the digital reading factor in the analysis makes us propose a cautious interpretation that such additional demands might be involved in digital reading.

One tentative explanation of this result is that visual-spatial skills may be involved to a larger extent in digital reading compared to traditional reading. They can, for instance, be assumed to promote certain aspects of digital reading such as the managing of non-sequential page structures and navigating in hypertexts. This way of reasoning is in line with, and supported by, some previous studies reviewed in the background section (e.g., Castelli, Colazzo, \& Molinari, 1998; Lee, 2007; Zhang \& Salvendy, 2001). However, it seems reasonable to believe that not only cognitive aspects but also contextual and emotional components like interest and attitudes towards the medium may affect students' performance (cf., Anmarkrud \& Bråten, 2009; McKenna et al., 2012; Retelsdorf et al., 2011).

Our second research question deals with gender differences in the two reading tests. The result that the girls would outperform the boys in overall reading performance was, of course, expected not only from the analysis of the larger national sample reported by the OECD (2010), but also from a substantial body of national and international research on gender differences in reading performance. In addition, the lessening gap between males and females, when it comes to digital reading, was verified in our analysis. However, as this effect was perfectly mediated by the factor related to time spent playing computer games, we will return to this issue later, along with the third research question. The fact that a 
difference to the boys' advantage was found in the "integrate and interpret" aspect of traditional reading is noteworthy, and the reason for this can only be speculated upon. However, the picking up of information from graphic representations like diagrams, maps, and so on is, to some extent, included in this aspect. The supposition that this may be of importance is based on research on the Swedish Scholastic Aptitude Test, where it is well known that males perform better than females on the Diagram, Tables, and Maps (DTM) test (e.g., Åberg-Bengtsson, 1999, 2005). It does not seem too far-fetched to presume that this has to do with gender differences in visual-spatial ability, although Åberg-Bengtsson found a quantitative or numeric factor to also be involved.

In our third research question, we address the issue of playing computer games and gender differences in digital reading performance. Our results show, on the one hand, that the students' performance on digital reading was related to time spent on playing computer games and, on the other hand, that boys performed somewhat better than girls with regard to digital reading when overall reading was controlled for. Even though the effects were rather small, it is a most interesting finding, that the boys' relatively better performance in this respect - a result also noted in the OECD (2010) report - was perfectly mediated by the computer game-playing factor. Tentatively this implies that, at least to some extent, computer game playing may enhance digital reading performance. Obviously, there are several plausible explanations to this. If accepting that visual-spatial ability may be involved in the digital reading factor and boys' well-documented higher spatial ability (e.g., Bennett et al., 1974; Maccoby \& Jacklin, 1974; McGee, 1979) this would explain the boys' better performance in digital reading before adding the Play factor. The fact that this effect was mediated by time spent on computer games may be explained by results from previous research that visual-spatial ability not only relates to, but is also enhanced by, playing computer games (McClurg \& Chaillé, 1987; Okagaki \& Frensch, 1994; Subrahmanyam \& Greenfield, 1994). Perhaps the boys have acquired additional visual-spatial skills by playing computer games to a greater extent than girls.

It is not unlikely that there may be spiraling effects involved, working in several directions. Maybe, the boys' better visual-spatial abilities promote their interest in playing computer games, which, in turn, may enhance their visual-spatial abilities. To our knowledge, however, no one has studied if persons who already have good visual-spatial skills become more interested in computer games. The possibility that boys had more experience and interest in visiting different game sites on the Internet, and thus simply felt more comfortable with the environment offered in the digital test, is an additional explanation to be considered. This is in line with the suggestions by McKenna et al. (2012) that the attitude towards the medium and the type of text is of importance for the performance. Still another explanation for the fact that time spent playing computer games was found to influence digital reading performance and might affect the ability to read images per se. Greenfield (1996), for instance, has suggested that playing computer games enhances image-reading skills. Other researchers have argued that the making of the meaning of a variety of semiotic modes, among other things the ability to read images, is an important part of digital reading (Kress \& Van Leeuwen, 1996; Rasmusson \& Eklund, 2013).

\section{Implications for Education}

The use of the Internet has increased remarkably among Swedish youngsters during the past decade. This increase is larger among boys than among girls. During the same period, the 
reading of books has decreased, but not as much as the use of other media such as newspapers, radio, and video. To improve students' reading ability (in general) and boys' reading ability (in particular) is an important issue for education. It is well known that the reading of books improves reading literacy. It seems as if the activities on the Internet, often characterized by the reading of shorter texts, do not enhance traditional reading skills in the same way as longer and more coherent texts. It is possible to see these new reading habits from two different perspectives.

From one point of view, the school has a mission to educate and prepare the students for a working life as fully functional members of the society. Being able to read longer texts, for example novels, and thus connect with their cultural heritage, is traditionally considered valuable. From another point of view, altered reading competencies are new necessities required in contemporary society. Quick cursory readings, and the ability to navigate, integrate and evaluate shorter texts, demanded by the new technologies must be mastered by all and everyone and are thus a mission for the educational system. Some implications for education would be to adapt the curriculum, the teachings, and the assessments in line with these new demands. To date, the Swedish schools offer a very limited instruction in digital reading.

\section{A Final Remark}

The research presented here has certain limitations. What we have labeled digital reading refers to one particular kind of reading on the Internet measuring aspects that are brought to the fore in the PISA 2009 assessment. Our analysis should be read with this in mind. Furthermore, only two questions from the students' questionnaire address computer habits and both concern time spent on computer games.

The possible explanations to the effect of computer game playing on digital reading found in the present study and reflected upon above, all build upon indirect extrapolations of research on, for instance, computer games or experience in computer environments, on the one hand, and visual-spatial abilities, the reading of images, and so on, on the other. Obviously, as there is a lack in the PISA data of, for instance, a measure of visual-spatial abilities and much of our argumentation builds upon the boys' oft-reported better performance in this respect, this delimits our study. Thus, further studies targeted more directly towards investigating the relationships between computer habits, cognitive abilities, and digital reading abilities are certainly asked for, in addition to the more obvious issue of demands on digital reading literacy in contemporary society.

\section{References}

Åberg-Bengtsson, L. (1999). Dimensions of performance in the interpretation of diagrams, tables, and maps: Some gender differences in the Swedish Scholastic Aptitude Test. Journal of Research in Science Teaching, 36(5), 565-582. doi:10.1002/(SICI)1098-2736(199905)36:5<565::AIDTEA4>3.0.CO;2-L

Åberg-Bengtsson, L. (2005). Separating quantitative and analytic dimensions in the Swedish Scholastic Aptitude Test (SweSAT). Scandinavian Journal of Educational Research, 49(4), 359-383. doi:10.1080/00313830500202892

Anmarkrud, Ø., \& Bråten, I. (2009). Motivation for reading comprehension. Learning and Individual Differences, 19(2), 252-256. doi:10.1016/j.lindif.2008.09.002 
Asher, S. R., \& Gottman, J. M. (1973). Sex of teacher and student reading achievement. Journal of Educational Psychology, 65, 168-171. doi:http://dx.doi.org/10.1037/h0034986

Asparouhov, T. (2009). Multilevel Data/Complex Sample: Weighting [Online forum comment]. Retrieved from http://www.statmodel.com/discussion/messages/12/3975.html

Bennett, G. K., Seashore, H. G., \& Wesman, A. G. (1974). Manual for the differential aptitude tests: Form $S$ and T (5th ed.). New York, NY: The Psychological Association.

Carroll, J. B. (1993). Human cognitive abilities: A survey of factor analytic studies. New York, NY: Cambridge University Press.

Castelli, C., Colazzo, L., \& Molinari, A. (1998). Cognitive variables and patterns of hypertext performances: Lessons learned for educational hypermedia construction. Journal of Educational Multimedia and Hypermedia, 7(2-3), 177-206. Retrieved from http://www.aace.org/pubs/jemh/

Coiro, J. (2003). Exploring literacy on the Internet. Reading comprehension on the Internet: Expanding our understanding of reading comprehension to encompass new literacies. Reading Teacher, 56 (5), 458-464. Retrieved from http://www.jstor.org/stable/20205224

Coiro, J. (2011). Talking about reading as thinking, modeling the hidden complexities of online reading comprehension. Theory Into Practice, 50, 107-115. doi:10.1080/00405841.2011. 558435

Coiro, J., \& Dobler, E. (2007). Exploring the online reading comprehension strategies used by sixthgrade skilled readers to search for and locate information on the Internet. Reading Research Quarterly, 24(2), 214-257. doi:10.1598/RRQ.42.2.2

Coleman, J. S. (1988). Social capital in the creation of human capital. American Journal of Sociology, 94, S95-S120. Retrieved from http://www.jstor.org/stable/2780243

Donahue, P., Finnegan, R., Lutkus, A., Allen, N., \& Campbell, J. (2001). The nation's report card: Fourth-grade reading 2000 (NCES 2001-499). Washington, DC: US Government Printing Office.

Elley, W. B., (Ed.). (1994). The IEA study of reading literacy: Achievement and instruction in thirtytwo school systems [International studies in Educational Achievement]. Exeter, UK: Pergamon.

Feng, J., Spence, I., \& Pratt, J. (2007). Playing an action video game reduces gender differences in spatial cognition. Psychological Science, 18, 850-855. doi:10.1111/j.1467-9280.2007.01990.x

Gates, A. I. (1961). Sex differences in reading ability. Elementary School Journal, 61(8), 431-434. Retrieved from http://www.jstor.org/stable/999823

Gee, J. P. (2003). What video games have to teach us about learning and literacy. New York, NY: PalGrave-McMillan.

Greenfield, P. M. (1996). Video games as cultural artefacts. In P. M. Greenfield \& R. R. Cocking (Eds.), Interacting with video (pp. 35-46). Norwood, NJ: Ablex.

Greenfield, P. M., Camaioni, L. E., Ercolani, P., Weiss, L., Lauber, B. A., \& Perucchini, P. (1996). Cognitive socialization by computer games in two cultures: Inductive discovery or mastery of an iconic code? Special issue: Effects of interactive entertainment technologies on development. In P.M. Greenfield \& R.R. Cocking (Eds.), Interacting with video (pp. 141-168). Norwood, NJ: Ablex.

Greenfield, P. M., DeWinstanley, P., Kilpatrick, H., \& Kaye. D. (1994). Action video games and informal education: Effects on strategies for dividing visual attention. Journal of Applied Developmental Psychology, 15(1), 105-123. doi:10.1016/0193-3973(94)90008-6

Gustafsson, J.-E. (1994). Dimensions of ability measured by the Swedish Scholastic Aptitude Test. Paper presented at the Annual Meeting of American Educational Research Association, April, New Orleans.

Gustafsson, J.-E., \& Balke, G. (1993). General and specific abilities as predictors of school achievement. Multivariate Behavioral Research, 28, 407-434. doi:10.1207/s15327906mbr2804_2

Gustafsson, J.-E., \& Stahle, P.A. (2005). STREAMS 3.0 user's guide: Version 1.0.0. Mölndal, Sweden: MultivariateWare. 
Jöreskog, K. G., \& Sörbom, D. (1993). LISREL 8: Structural equational modeling with SIMPLIS command language. Chicago, IL: Scientific Software International.

Kress, G., \& Van Leeuwen, T. (1996). Reading images: The grammar of visual design. London: Routledge.

Lee, H. (2007). Instructional design of web-based simulations for learners with different levels of spatial ability. Instructional Science, 35, 467-479. doi:10.1007/s11251-006-9010-5

Leu, D. J., Zawilinski, L., Castek, J., Banerjee, M., Housand, B., Liu, Y., \& O’Neil, M. (2007). What is new about the new literacies of online reading comprehension? In A. Berger, L. Rush, \& J. Eakle (Eds.), Secondary school reading and writing: What research reveals for classroom practices (pp. 37-68). Chicago, IL: NCTE/NCRLL.

Maccoby, E. E., \& Jacklin, C.N. (1974). The psychology of sex differences. Stanford, CA: Stanford University Press.

McClurg, P. A., \& Chaille, C. (1987). Computer games: Environments for developing spatial cognition. Journal of Educational Computing Research, 3(1), 95-111. doi:10.2190/9N5U-P3E9R1X8-0RQM

McGee, M. G. (1979). Human spatial abilities: Sources of sex differences. New York, NY: Praeger Press.

McKenna, M. C., Conradi, K., Lawrence, C., Jang, B. G., \& Meyer, J. P. (2012). Reading attitudes of middle school students: Results of a US Survey. Reading Research Quarterly, 47, 283-306. doi:10.1002/rrq.021

Muthén, B. O., \& Satorra, A. (1995). Complex sample data in structural equation modeling. Sociological Methodology, 25, 267-316. Retrieved from http://www.jstor.org/stable/271070

Muthén, L. K., \& Muthén, B. O. (2012). Mplus user's guide (7th ed.). Los Angeles, CA: Muthén \& Muthén.

Newkirk, T. (2000). Misreading masculinity: Speculations on the great gender gap in writing. Language Arts, 77, 294-300. Retrieved from http://www.jstor.org/stable/41483068

Okagaki, L., \& Frensch, P.A. (1994). Effects of video game playing on measures of spatial performance: Gender effects in late adolescence. Journal of Applied Developmental Psychology, 15, 33-58. doi:10.1016/0193-3973(94)90005-1

Organisation for Economic Cooperation and Development [OECD], (2009a). PISA 2009 assessment framework: Key competencies in reading, mathematics, and science. Paris: OECD publications.

OECD (2009b). PISA data analysis manual, SPSS® (2nd ed.). Paris: OECD publications.

OECD (2010). What students know and can do: Student performance in reading, mathematics and science. (PISA 2009 results: Volume I). doi: http://dx.doi.org/10.1787/9789264091450-en

OECD (2011). Students on-line: Digital technologies and performance (PISA 2009 results: Volume VI). doi: http://dx.doi.org/10.1787/9789264112995-en

OECD (2012). PISA 2009 Technical Report, PISA, Paris: OECD Publishing. doi: http://dx.doi.org/10. 1787/9789264167872-en

Pan, B., Hembrooke, H.A., Gay, G.K., Granka, L.A., Feusner, M.K., \& Newman, J.K. (2004). The determinants of web page viewing behaviour: An eye-tracking study. Proceedings of the 2004 symposium on eye tracking research \& applications, 147-154. doi:10.1145/968363.968391

Preacher, K. J., \& Hayes, A. F. (2008). Asymptotic and resampling strategies for assessing and comparing indirect effects in multiple mediator models. Behavior Research Methods, 40(3), 879-891. doi:10.3758/BRM.40.3.879

Protopsaltis, A., \& Bouki, V. (2009). Gender patterns in hypertext reading. Ergonomics Open Journal, 2, 104-113. Retrieved from http://benthamopen.com/toergj/articles/V002/SI0047TOERGJ/ 104TOERGJ.pdf

Rasmusson, M., \& Eklund, M. (2013). "It's easier to read on the Internet—you just click on what you want to read...": Abilities and skills needed for reading on the Internet. Education and Information Technologies, 18(3), 401-419. doi: 10.1007/s10639-012-9190-3. 
Retelsdorf, J., Köller, O., \& Möller, J. (2011). On the effects of motivation on reading performance growth in secondary school. Learning and Instruction, 21(4), 550-559. doi:10.1016/j. learninstruc.2010.11.001

Rosén, M. (2001). Gender differences in reading performance on documents across countries. Reading and Writing: An Interdisciplinary Journal, 14, 1-38. doi:10.1023/A:1007995107442

Smith, M., \& Wilhelm, J. (2002). "Reading don't fix no Chevys": Literacy in the lives of young men. Portsmouth, NH: Heinemann.

Strømsø, H. I., Bråten, I., \& Samuelstuen, M. S. (2008). Dimensions of topic-specific epistemological beliefs as predictors of multiple text understanding. Learning and Instruction, 18, 513-527. doi:10.1016/j.learninstruc.2007.11.001

Subrahmanyam, K., \& Greenfield, P. M. (1994). Effect of video game practice on spatial skills in girls and boys. Journal of Applied Developmental Psychology, 15(1), 13-32. doi:10.1016/0193-3973 (94)90004-3

Swedish National Agency for Education (2011). Eleverna och nätet: PISA 2009 om 15-åringars förmåga att söka, läsa och värdera digital information [Students and the Internet]. Stockholm: Skolverket.

Taube, K., \& Munck, I. M. (1996). Gender differences at the item level. In H. Wagemaker (Ed.), Are girls better readers? Gender differences in reading literacy in 32 countries (pp. 53-77). The Hague: IEA.

Thomson, S., \& De Bortoli, L. (2012). Preparing Australian students for the digital world: Results from the PISA 2009 digital reading literacy assessment. Camberwell, Vic: Australian Council for Educational Research. Retrieved from http://research.acer.edu.au/ozpisa/10

Wagemaker, H. (Ed.). (1996). Are girls better readers? Gender differences in reading literacy in 32 countries. The Hague: IEA.

Zhang, H., \& Salvendy, G. (2001). The implications of visualisation ability and structure preview design for web information search tasks. International Journal of Human-Computer Interaction, 13(1), 75-95. doi:10.1207/S15327590IJHC1301_5 